\title{
Near-field pollutant dispersion in the built environment by CFD and wind tunnel simulations
}

\author{
Mauricio Chavez ${ }^{*}$, Bodhisatta Hajra ${ }^{1}$, Ted Stathopoulos ${ }^{1}$ and Ali Bahloul ${ }^{2}$ \\ ${ }^{1}$ Department of Building, Civil and Environmental Engineering, Concordia University, 1455 De \\ Maisonneuve West, Montreal, Quebec, Canada H3G 1 M8 \\ ${ }^{2}$ Institut de recherche Robert-Sauvé en santé et en sécurité du travail (IRSST), 505 De Maisonneuve \\ West, Montréal, Canada H3A 3C2 \\ *Corresponding email: mau_chav@encs.concordia.ca
}

\begin{abstract}
Buildings are always found to be in the vicinity of other buildings, especially in urban areas. This causes effluents released from stacks located on one of the buildings to re-enter the same or an adjacent building, generating potential health problems to the occupants of the building. Earlier, Computational Fluid Dynamics (CFD) has been used in simulating pollutant transport for isolated buildings, with only few studies examining the effects of adjacent buildings. In this paper three cases that include an isolated low-rise building (source), a taller building placed upwind of the source and a case with taller buildings placed upwind and downwind of the source were considered. CFD simulations using the Realisable k- $\varepsilon$ model for different turbulent Schmidt numbers $\left(\mathrm{Sc}_{\mathrm{t}}\right)$ and wind tunnel experiments were performed for these cases. ASHRAE 2007 was also used to assess plume dispersion for the isolated building. It was found that a strong dependence of $\mathrm{Sc}_{\mathrm{t}}$ on CFD simulations of pollutant transport exists for the isolated building configuration. However, variations of $\mathrm{Sc}_{\mathrm{t}}$ have less impact on assessing pollutant dispersion in the presence of adjacent buildings. The ASHRAE 2007 model predicted very low dilutions for the isolated building, making it necessary to re-visit its formulations.
\end{abstract}

Keywords: Pollution; Dispersion; CFD; Schmidt number; Multiple building; Reingestion; Stack; Wind tunnel 


\section{INTRODUCTION}

Assessing pollutant concentrations in the built environment is challenging because of the complexity of airflow around a multiple building configuration. Assuming that pollutants are transported by the wind it would be expected that exhaust gases from roof top stacks are effectively diluted and acceptable concentrations for human health are reached at the ground level. However, when pollutants are released from roof stacks within an urban environment, they can be trapped in recirculation zones and may impinge on sensitive zones, for example the fresh air intakes, which are usually located at the sides of buildings. This polluted air may not just have the tendency to re-enter the building forming a closed circuit path known as re-ingestion, but can also affect an adjacent building located downwind or upwind of the emitting building (Wilson et al., 1998). The resulting degradation of the indoor air quality is recognized as an important risk factor for human health such as respiratory diseases, heart and brain damage to the occupants of the building (Stathopoulos et al. 2004). Unfortunately, the state of art has not been sufficiently advanced to allow building engineers to apply appropriate design criteria to avoid this problem for new construction or help alleviate it for existing buildings.

Currently, the techniques available to assess pollutant concentrations in the built environment include field measurements, wind tunnel tests, CFD and other semiempirical models such as ASHRAE 2007. A recent study found that most available semiempirical models such as AFTOX, SCREEN, etc. cannot be used for near-field pollutant dispersion problems (Hajra et al., 2010). ASHRAE 2007 is used for isolated buildings and does not incorporate the effects of adjacent buildings (Stathopoulos et al., 2008). Although wind tunnel and field studies are useful in predicting plume dilutions, time and financial constraints are two of the major disadvantages associated with them (Blocken et al., 2008). CFD has been used by various researchers to study plume released from isolated buildings and results obtained for different Schmidt numbers $\left(\mathrm{Sc}_{\mathrm{t}}\right)$ showed discrepancies (Tominaga and Stathopoulos, 2007). Therefore, it is necessary to study the variations of this number $\left(\mathrm{Sc}_{\mathrm{t}}\right)$ in pollutant dispersion studies, particularly in the presence of adjacent buildings, since most CFD studies have not included the effect of adjacent buildings. 
The aim of the present study is to simulate pollutant dispersion within a multiple building configuration. In particular, the investigation is focused on the near field dispersion based on CFD using RANS equations and wind tunnel modelling. It should be noted that the "near field" concept used in this study involves the fluid mechanical interaction between two or three consecutive buildings. Different definitions of near field dispersion are available in the literature as the field study conducted by Dobre et al. (2005) where "near field" was the proximity of an urban intersection. In the present work three different configurations have been considered: a low-rise isolated building (emitting building), a taller building placed upstream of the emitting building and a third case involving a tall building placed upstream and downstream of the emitting building. Comparisons with wind tunnel results were made for validation purposes. CFD simulations were carried out using the Realisable $\mathrm{k}-\varepsilon$ model and the effect of different $\mathrm{Sc}_{\mathrm{t}}$ on dispersion has been discussed. Literature field results from Stathopoulos et al. (2008) were also used for comparisons in some cases.

\section{CFD SIMULATIONS}

CFD is a useful tool for simulation of turbulent flow and pollutant dispersion around buildings. Commercially available FLUENT is one of the widely used tools incorporating several turbulence models (FLUENT Inc., 2003). The present work used FLUENT version 6.2.16. Past studies have shown that the unsteady Large Eddy Simulation (LES) models have a better agreement with experimental results in pollutant dispersion problems. However, the computational cost associated with LES is about 100 times greater than that required by using the steady Reynolds-Averaged Navier Stokes (RANS) models (Cheng et al., 2003). The effects of different turbulence models have been tested in previous pollutant dispersion studies, but definitive statements are not available in the literature. The reason is that turbulence models performance of flow around buildings is highly dependent on the application and mesh resolution (Franke et al., 2007). However important observations concerning RANS k- $\varepsilon$ have been noted by Tominaga and Stathopoulos (2009). The Standard k- $\varepsilon$ provides inadequate concentration fields due to 
the inaccuracy in reproducing of basic flow structure, for instance reverse flow on the roof. The RNG and Realizable models provide similar results and show much better agreement with experimental data. The present study employed the Realizable k- $\varepsilon$ model since Fluent does not allow to modify the turbulent Schmidt number $\left(\mathrm{Sc}_{\mathrm{t}}\right)$ for the RNG model (FLUENT Inc., 2003).

$\mathrm{Sc}_{\mathrm{t}}$ is necessary to solve the transport mass equation in CFD prediction of dispersion with RANS (Tominaga and Stathopoulos, 2007) and is defined as the ratio of turbulent momentum diffusivity (eddy viscosity) to the mass diffusivity $\left(\mathrm{Sc}_{\mathrm{t}}=\mathrm{v}_{\mathrm{t}} / \mathrm{D}_{\mathrm{t}}\right)$. In Fluent $\mathrm{Sc}_{\mathrm{t}}$ must be declared as an input before any calculation or else the default value is 0.7 . The current calculation selected $\mathrm{Sc}_{\mathrm{t}}$ of $0.1,0.3$ and 0.7 ; because some previous studies have found good agreement between numerical and experimental results for tracer experiments involving isolated building, for these values (Blocken et al., 2008).

Some researchers have also expressed $\mathrm{Sc}_{\mathrm{t}}$ in terms of a ratio of the stability correction factor for mass and momentum flux (Flesch et al., 2002). Turbulent Schmidt numbers have been measured in the wind tunnel by various researchers in the past (Koeltzsch, 2000, Flesch et al., 2002). $\mathrm{Sc}_{\mathrm{t}}$ is considered constant in most CFD studies in pollutant dispersion and negligible changes in $\mathrm{Sc}_{\mathrm{t}}$ were found with a change in atmospheric stability (Flesch et al., 2002). However, tracer experiments carried out by Koeltzsch (2000) have confirmed a strong dependence of height within the boundary layer affecting the value of $\mathrm{Sc}_{\mathrm{t}}$. In the present study, $\mathrm{Sc}_{\mathrm{t}}$ can be measured at the height $0.075 \mathrm{~m}$ in the wind tunnel (representing a full-scale value of $15 \mathrm{~m}$ ) using formulations proposed in previous studies as shown in Table 1. These formulations are empirical equations based on experimental results. Rotta (1964) developed his equation based on temperature distribution within turbulent boundary layer; Pruitt et al., (1973) used field measurements of wet and dry bulb temperature; Dyer and Bradley (1982) also conducted field measurements to determine flux gradient relationship; Hogstrom (1996) used previous field data to develop a new set of equations and Koeltzsch (2000) performed turbulent measurements of a horizontal plate in a wind tunnel.

Table 1. Values of $\mathrm{Sc}_{\mathrm{t}}$ in previous studies 


\begin{tabular}{|l|l|l|}
\hline Previous studies & Formulation & $\begin{array}{l}\text { Value of } \mathrm{Sc}_{\mathrm{t}} \\
(\mathrm{y}=0.075 \mathrm{~m})\end{array}$ \\
\hline Rotta, 1964 & $\begin{array}{l}\mathrm{Pr}_{\mathrm{t}}=0.9-0.4(\mathrm{y} / \delta)^{2} \\
\delta: \text { boundary layer thickness }=0.9 \mathrm{~m} \\
\mathrm{y}: \text { distance above the ground within the boundary } \\
\text { layer } \\
\text { Turbulent Prandtl number }\left(\mathrm{Pr}_{\mathrm{t}}\right) \text { considered similar to } \\
\text { turbulent Schmidt number. }\end{array}$ & 0.89 \\
\hline Pruitt et al., 1973 & $\begin{array}{l}\mathrm{Sc}_{\mathrm{t}}=\varphi_{\mathrm{c}} / \varphi_{\mathrm{m}}, \text { where } \varphi_{\mathrm{m}}=(1+16(\mathrm{y} / \mathrm{L})) \text { and } \\
\varphi_{\mathrm{c}}=0.89(1+34(\mathrm{y} / \mathrm{L})) \\
\varphi_{\mathrm{m}}: \text { momentum flux } \\
\varphi_{\mathrm{c}}: \text { mass flux } \\
\mathrm{L}: \text { Monin Obukhov length }=54200 \\
\mathrm{y}: \text { same as previous }\end{array}$ & 0.88 \\
\hline Dyer and Bradley, & $\begin{array}{l}\mathrm{Sc}_{\mathrm{t}}=\varphi_{\mathrm{c}} / \varphi_{\mathrm{m}}, \text { where } \varphi_{\mathrm{m}}=1+4.8(\mathrm{y} / \mathrm{L}) \text { and } \varphi_{\mathrm{c}}=0.95 \\
+4.5(\mathrm{y} / \mathrm{L}) \\
\varphi_{\mathrm{m}}, \varphi_{\mathrm{c}}, \mathrm{L} \text { and y same as previous }\end{array}$ & 0.95 \\
\hline Hogstrom, 1996 & $\begin{array}{l}\mathrm{Sc}_{\mathrm{t}}=\varphi_{\mathrm{c}} / \varphi_{\mathrm{m}}, \text { where } \varphi_{\mathrm{c}}=\varphi_{\mathrm{m}}=1+5.3(\mathrm{y} / \mathrm{L}) \\
\varphi_{\mathrm{m}}, \varphi_{\mathrm{c}}, \mathrm{L} \text { and y same as previous }\end{array}$ & 1 \\
\hline Koeltzsch, 2000 & $\begin{array}{l}S c_{t}=\sum_{i=0}^{5} a_{i}(z / \delta)^{i}, \text { where a }=(.0 .226,12.2,46.2, \\
81,-67.9 \text { and } 21.5) \\
\delta \text { and y same as previous }\end{array}$ & 0.55 \\
\hline
\end{tabular}

\section{METHODOLOGY}

\subsection{Description of cases considered}

Three different cases have been considered as shown in Figure 1. The dimensions of each building are shown in Table 2 . 
Case 1: B1 isolated (emitting building)

Case 2: B1 and B2 upstream of B1

Case 3: B1, B2 upstream of B1 and B3 downstream of B1

Figure 1

Table 2.Building models for CFD and wind tunnel experiments

\begin{tabular}{|c|c|c|c|}
\hline Building & Height $(\mathrm{m})$ & Width $(\mathrm{m})$ & Length(m) \\
\hline B1 & $0.075(15)$ & $0.25(50)$ & $0.25(50)$ \\
\hline B2 & $0.15(30)$ & $0.25(50)$ & $0.15(30)$ \\
\hline B3 & $0.27(54)$ & $0.22(44)$ & $0.075(15)$ \\
\hline
\end{tabular}

NB: Values represent the wind tunnel model dimensions (1:200). Full-scale dimensions are those in parenthesis. Width refers to the dimension which is perpendicular to wind direction.

For all cases a single wind direction perpendicular to the building face was considered. Dilution concentration measurements were carried out using receptors (4 upwind and 6 downwind the stack) located centrally on the rooftop of B1 (emitting building) and spaced $0.025 \mathrm{~m}$ apart and $0.125 \mathrm{~m}$ from the lateral edges, as shown in Figure 2 (a). For Case 3, 10 receptors were also placed along the windward wall of B3 starting at $0.004 \mathrm{~m}$ from the ground. These receptors were located centrally, $0.025 \mathrm{~m}$ apart starting at $0.075 \mathrm{~m}$ from the ground. The stack location for all cases was $0.1 \mathrm{~m}$ from the upwind edge of B1 and $0.125 \mathrm{~m}$ from the lateral edges.

\subsection{Normalized dilution}

If a pollutant is discharged with a certain initial concentration, this concentration will be reduced as the pollutant travels within the atmosphere mixing with clean air. Then, dilution is defined as the ratio between the source concentration with measured 
concentration at a specific point. Therefore, the lower the measured concentration the higher the dilution value will be.

Since Fluent gives results in terms of concentrations, the following formulation, suggested by Wilson (1979), was used to evaluate the normalized dilution:

$$
D_{\text {normalized }}=\frac{D_{r} Q}{U_{H} H^{2}}
$$

where,

$D_{r}=C_{e} / C_{r}$ is the dimensionless concentration coefficient at the coordinate location (receptor).

$C_{e}=$ contaminant mass fraction in exhaust $(\mathrm{ppm})$.

$C_{r}=$ contaminant mass fraction at the coordinate location (ppm).

$\mathrm{Q}$ is the flow rate at the exhaust $\left(\mathrm{m}^{3} / \mathrm{s}\right)$.

$U_{H}$ is the wind speed at the B1 height $(H)$, in this case $U_{H}=6.1 \mathrm{~m} / \mathrm{s}(\mathrm{H}=0.075 \mathrm{~m})$.

The gas used for the wind tunnel experimentation was Sulphur hexafluoride $\left(\mathrm{SF}_{6}\right)$ and the momentum ratio at the stack outflow is $\mathrm{M}=\mathrm{V}_{\mathrm{e}} / \mathrm{U}_{\mathrm{H}}$ (where $\mathrm{V}_{\mathrm{e}}$ is the exhaust velocity).

\subsection{Wind tunnel experimental set up}

The wind tunnel experiments were carried out in the open circuit variable height boundary layer wind tunnel of Concordia University. Its dimensions are $1.8 \mathrm{~m}$ by $1.8 \mathrm{~m}$ in section and $12.2 \mathrm{~m}$ in length. The buildings tested were made of timber on a 1:200 scale. A mixture of $\mathrm{SF}_{6}$ and Nitrogen with a concentration of $10 \mathrm{ppm}$ was released from a simulated stack with full-scale equivalent heights of $1 \mathrm{~m}$ and exhaust momentum $\mathrm{M}$ equal to 1 and 3 .

For correct modelling of non-buoyant plume exhaust in the wind tunnel, Snyder (1981) suggests to respect the following criteria:

a) Geometric similarity:

The geometry (shape) between full-scale and wind tunnel should be similar. To this end a scale of 1:200 is used for all linear dimensions. 
b) Building Reynolds Number $\left(\operatorname{Re}_{b}\right)>11000$

$\operatorname{Re}_{\mathrm{b}}=\left(\rho \mathrm{U}_{\mathrm{H}} \mathrm{D}\right) / \mu$ where $\rho$ and $\mu$ are the density and dynamic viscosity of air, $\mathrm{U}_{\mathrm{H}}$ is the wind velocity at the building height in the wind tunnel and D is the significant obstruction dimension perpendicular to wind direction in wind tunnel scale. If the value of $\underline{\mathrm{Re}_{b}}$ is sufficiently large (> 11000) the flow field becomes independent of $\mathrm{Re}_{\mathrm{b}}$.

c) Stack Reynolds Number $\left(\operatorname{Re}_{\mathrm{s}}\right)>2000$

$\operatorname{Re}_{\mathrm{s}}=\left(\rho \mathrm{V}_{\mathrm{e}} \mathrm{D}\right) / \mu$ where $\rho$ and $\mu$ are the density and dynamic viscosity of air, $\mathrm{V}_{\mathrm{e}}$ is the exhaust speed at the stack in the wind tunnel, and D is the internal diameter of the stack in wind tunnel scale. A value of 2000 is well established for the maintenance of turbulent flow in a pipe.

d) Similarity of wind tunnel flow with atmospheric surface layer

The wind flow in the Boundary Layer wind tunnel represents an urban terrain with power law exponent of 0.33. Roughness elements and spires were used to generate the desired terrain roughness. The model value of the longitudinal integral scale was $0.4 \mathrm{~m}$, which corresponds to a full-scale value of $80 \mathrm{~m}$. The model roughness length of the upstream exposure was $0.0033 \mathrm{~m}$, which corresponds to a full-scale roughness length of $0.66 \mathrm{~m}$.

\section{e) Equivalent stack momentum ratio}

Exhaust momentum $(\mathrm{M})$ is defined as $\mathrm{M}=\left(\rho_{\mathrm{e}} / \rho_{\mathrm{a}}\right)\left(\mathrm{V}_{\mathrm{e}} / \mathrm{U}_{\mathrm{H}}\right)$ where $\rho_{\mathrm{e}}$ and $\rho_{\mathrm{a}}$ are density of exhaust gas and ambient air, $V_{e}$ is the exhaust speed and $U_{H}$ is the wind speed at the building height. According to Snyder (1981) the value of "M" in the full scale and wind tunnel has to be equal for accurate simulation of tracer gas studies. Generally for nonbuoyant plumes, the term $\left(\rho_{\mathrm{e}} / \rho_{\mathrm{a}}\right)$ is omitted from the expression. For the present study the cylinder containing a mixture of $\mathrm{SF}_{6}$ and Nitrogen had $10 \mathrm{ppm}$ concentration of $\mathrm{SF}_{6}$ in it. This implies that the gas released from the stack in the wind tunnel is practically Nitrogen (density near to the ambient air).

A multi-syringe pump was used to collect the gas samples to determine the concentration of effluents at various rooftop receptors of B1. According to ASHRAE 
2007, when the source and receptors lie in the same recirculation zone, as in the present study, concentration values obtained up to an averaging time of 2 minutes in the wind tunnel correspond to full-scale averaging time of one hour. For the present study the averaging time for collection of the samples in the experiments carried out in the wind tunnel was only $1 \mathrm{~min}$, since the instrument is capable of measuring samples at the maximum averaging time of $1 \mathrm{~min}$. This is not expected to affect the accuracy of the measurements, as discussed further in Stathopoulos et al., 2004. Some measurements were also done on the adjacent buildings, more precisely, on the leeward and windward walls of $\mathrm{B} 2$ and $\mathrm{B} 3$ respectively. $\mathrm{SF}_{6}$ gas was released from a tube connecting the mass flow controller and mass flow transducer regulating its flow from the stack. A Gas Chromatograph (GC) was used to assess the gas concentrations collected using the syringe samplers. Deviations in concentration measurements were usually within $\pm 10 \%$ (Stathopoulos et al., 2008). The tracer gas was released from the stack on the top of B1 building, as shown in Figure 2 (a).

A power law exponent of 0.33 was used to determine the velocity at building height $\left(\mathrm{U}_{\mathrm{H}}\right)$. This exponent yields the best approximation of the inlet velocity profile in the wind tunnel corresponding experiments. The model value of the longitudinal integral scale was $0.4 \mathrm{~m}$, which corresponds to a full-scale value of $80 \mathrm{~m}$. The model roughness length of the upstream exposure was $0.0033 \mathrm{~m}$, which corresponds to a full-scale roughness length of $0.66 \mathrm{~m}$. This value is possible for a heavy suburban or lower roughness urban exposure corresponding to a power law exponent of 0.33. For further details, please see Stathopoulos et al. (2008).

\subsection{CFD model and boundary conditions}

The numerical model was constructed principally using structured hexahedra grids since it has been proved that this mesh style provides the best computational results (Hefny and Ooka, 2009). Due to the circular section of the stack an unstructured wedge grid has been used in its vicinity. Three meshes (fine, medium and coarse) were produced changing the 
number of divisions of the circumference at the bottom of the stack and the number of elements at the edges of the isolated building, B1. The expansion ratio between two consecutive cells was limited to 1.25. The comparison of normalized dilution in a specific point in the space showed similar values between medium and fine mesh. Then, the medium mesh was selected for this study. The stack circumference was divided into 10 elements and the largest element around the buildings was $1 \mathrm{~m}$. The total number of cells was between $0.9 \times 10^{6}$ to $1.5 \times 10^{6}$ depending on whether it was an isolated building or a multiple building configuration. For this study the convergence criterion for all residuals was fixed at $10 \mathrm{e}^{-5}$. Figure 2 (b) shows a perspective view of the mesh of isolated building case (B1).

Figure 2

The computational domain is a parallelepiped - see Figure 3. Based on recommendations of past studies, the dimensions of this domain are specified as follows: considering $\mathrm{H}$ as the building height in the model (case1), the lateral and the top boundary are $5 \mathrm{H}$ away from the building and the outlet boundary is $20 \mathrm{H}$ downwind from the building to allow flow development. In the cases 2 and 3 the added buildings have enough clearance from sides, upstream and downstream ends of the domain because $\mathrm{H}$ is the height of the taller building for each case. The applied distance for lateral boundaries is much larger than the wind tunnel section in all cases. This follows published recommendations to keep the blockage at $1.5 \%$ in order to reduce the influence of lateral walls on the region of interest (Franke et al., 2007; Tominaga and Stathopoulos, 2009). The bottom surface (i.e ground) is specified as a rigid plane with an aerodynamic roughness length $\mathrm{y}_{0}=0.0033 \mathrm{~m}$ (which corresponds to $\mathrm{y}_{0}=0.66 \mathrm{~m}$ at full scale) as mentioned previously. In Fluent this roughness length is implemented by the sand-grain roughness height $\mathrm{k}_{\mathrm{s}}(\mathrm{m})$ which can be defined using the function developed by Blocken et al. (2007): $\mathrm{k}_{\mathrm{s}}=9.793 \mathrm{y}_{0} / \mathrm{Cs}$, where Cs is a roughness constant. Considering the default value of $\mathrm{Cs}$ equal to $0.5, \mathrm{k}_{\mathrm{s}}$ should be specified as 0.0646. However, this value is limited to the distance $z_{p}$ of the centroid of the first cell to the bottom domain $\left(\mathrm{e} . \mathrm{g} \mathrm{z}_{\mathrm{p}}=0.0025 \mathrm{~m}\right)$ as imposed by Fluent. The effect of this limitation is translated as stream wise changes in the inlet vertical profile. Consequently, for the inlet a distance of $3 \mathrm{H}$ was adopted in order to minimize the 
development of streamwise gradients, as discussed in Blocken et al. (2007). As with the experiment, a power law exponent of 0.33 , which corresponds to a light urban terrain (Simiu and Scanlan, 1996) was used for the study. The velocity at the building B1 height was $6.1 \mathrm{~m} / \mathrm{s}$. The turbulent kinetic energy profile $(\mathrm{k})$ was calculated using $\mathrm{k}=0.5(\mathrm{IU} U) 2$ and turbulent intensity values $\left(\mathrm{I}_{\mathrm{U}}\right)$ measured in the current wind tunnel experiments. The dissipation rate profile $(\varepsilon)$ was defined as $\varepsilon=\mathrm{u}^{* 3} / \kappa y$ where $\kappa$ is the von Karman constant $(0.42)$ and $\mathrm{u}^{*}$ is the friction velocity obtained from the equation $\mathrm{u}(\mathrm{y}) / \mathrm{u}^{*}=1 / \kappa\left(\ln \left(\mathrm{y} / \mathrm{y}_{\mathrm{o}}\right)\right.$ with roughness length $\mathrm{y}_{0}=0.0033 \mathrm{~m}$. Top and sides of the domain were modelled as slip walls (zero shear slip). At the outlet an outflow (zero gradient) condition was specified, to generate a fully developed flow. For walls, the standard wall function was applied because $\mathrm{y}^{*}$ was between 30 and 300 in a large number of cells. The pollutant released from stack was simulated with $\mathrm{SF}_{6}$ for a particular exhaust momentum ratio $(\mathrm{M})$.

Figure 3

\section{RESULTS AND DISCUSSION}

\subsection{Qualitative comparison between all cases}

Firstly a general view of the computations in terms of velocity and dilution field is analysed for all cases mentioned previously. Figure 4 shows the comparison of predicted mean velocity magnitude for the middle vertical plan. This comparative view of results demonstrates the significant difference of velocity field behaviour when the building layout increases its complexity in the near-field environment.

Figure 4

Additional buildings induce more low wind speed zones between buildings. These zones are also characterized by the presence of high vorticity as it can be noticed by the streamlines in Figure 5.It is interesting to note the streamlines originating from the windward wall of B1 in the vertical cross section view of Figure 5 (b) are a consequence 
of three dimensionality of the flow. The plan view is a good complement to better visualize the flow behaviour.

Figure 5

Figure 6 shows contour lines of dilution field for all cases. Significant changes in plume behaviour can be noted when a taller building is placed upwind or both upwind and downwind from an emitting building. The isolated building case (Figure 6 (a)) shows the usual plume behaviour used for pollutant dispersion modelling. The stack exhaust is dragged downstream by the wind reducing its concentration by mixing with the atmospheric clean air. Examining the case with a taller upstream building (Figure 6 (b)), it is noticed that plume tends to move upstream the wind flow changing significantly the configuration of the dilution field in the near-field environment. The upstream displacement of the plume is caused by the wake swirl of B2 which is identified in Figures 5 (b). The upstream flow of the swirl drags the plume toward the upstream adjacent building (B2), polluting the high section of the building. It is important to note that between B2 and B1 and close to the ground level, the normalized dilution is higher than 10 (the graph scale is from 0 to 10). The high dilution in this zone is explained by the clean air coming from the sides as shown in the streamlines plan view of Figure 5 (b). If a taller building is added downstream, the recirculation zone in the wake of B2 is increased and more polluted air gets trapped within. In this case the entire leeward wall of B2 is polluted as it shown in Figure 6 (c).

Figure 6

\subsection{Pollutant dispersion around an isolated low-rise building (Case 1)}

The results obtained from wind tunnel, CFD for $\mathrm{Sc}_{\mathrm{t}}=0.3$ and 0.7 and ASHRAE-2007 for a $1 \mathrm{~m}$ high stack at $\mathrm{M}=1$, have been presented in terms of normalized dilutions in Figure 7 (a). Only receptors located downstream the stack were considered. Clearly CFD predicts lower dilutions than wind tunnel at $\mathrm{Sc}_{\mathrm{t}}=0.7$ at all receptors. However, at $\mathrm{Sc}_{\mathrm{t}}=$ 0.3 CFD results compare well with wind tunnel data. Significant differences are observed 
for a $1 \mathrm{~m}$ height stack at $\mathrm{M}=3$, as depicted in Figure 7 (b). CFD now at $\mathrm{Sc}_{\mathrm{t}}=0.1$ predicts comparable dilutions with wind tunnel data at all receptors. However, CFD generates very low dilutions at $\mathrm{Sc}_{\mathrm{t}}=0.3$ and 0.7 compared to wind tunnel indicating its unsuitability for the present case. It is difficult to generalise a particular $\mathrm{Sc}_{\mathrm{t}}$ in CFD due to the complex flow structure of pollutant transport and, therefore, the local flow characteristics must be considered before making a suitable choice of $\mathrm{Sc}_{\mathrm{t}}$ (Tominaga and Stathopoulos, 2007).

ASHRAE-2007 predicts very low dilutions (very conservative) at all receptors making it necessary to re-visit its formulations. Additional details can be found in Stathopoulos et al. (2008). Although, ASHRAE 2007 is based on wind tunnel experimental data the terrain roughness and turbulence generated due to local topography and buildings to assess plume dilutions have not been considered. Additionally, the plume rise equation of Briggs (1984) predicts low plume rise resulting in less plume spread along the roof of the building. Therefore, the dilutions predicted by ASHRAE are overly conservative. Additional limitations include its inability to simulate rooftop structures and assessing dilutions on the wall of the adjacent building (see Hajra et al., 2010).

Figure 7

\subsection{Pollutant dispersion in the presence of an upstream building (Case 2)}

Figure 8 presents normalized dilution comparisons between wind tunnel, CFD for different $\mathrm{Sc}_{\mathrm{t}}$ and ASHRAE-2007 for Case 2. Receptors were located on rooftop of B1 upwind and downwind the stack. In general, it is observed that a taller upstream building generates lower dilutions on the rooftop of the emitting building. Similar observations were made in the field study carried out by Stathopoulos et al. (2008) on a low-rise building with a taller upstream building at Concordia University. In that study very low dilutions were also registered at the rooftop of emitting building caused by the influence of the upstream building. Figure 8 (a) corresponds to a $1 \mathrm{~m}$ stack at $\mathrm{M}=1$. It is observed that dilutions from wind tunnel and CFD compare well for $\mathrm{Sc}_{\mathrm{t}}=0.7$ at receptors located 
downwind of the stack. However, wind tunnel data compare well with $\mathrm{CFD}$ at $\mathrm{Sc}_{\mathrm{t}}=0.3$ at the upwind edge of the building. ASHRAE-2007 again predicts very low dilutions.

Significant differences were found for a stack height of $1 \mathrm{~m}$ at $\mathrm{M}=3$, as shown in Figure 8 (b). Wind tunnel data compared well with $\mathrm{CFD}$ at $\mathrm{Sc}_{\mathrm{t}}=0.1$ at all receptors except nearer the stack, where the wind tunnel predicts higher dilutions than CFD at $\mathrm{Sc}_{\mathrm{t}}=0.3$ and 0.7, indicating the unsuitability of higher values of $\mathrm{Sc}_{\mathrm{t}}$ for this case. ASHRAE-2007 shows same values as Case 1 because in its formulation surroundings are not taken into account.

Figure 8

4.4. Pollutant dispersion in the presence of an upstream and downstream building (Case 3)

Figure 9 presents comparisons between wind tunnel, CFD for different $\mathrm{Sc}_{\mathrm{t}}$ and ASHRAE-2007 for Case 3. Receptors are located on rooftop receptors of B1 upwind and downwind the stack. In general, it is observed that the addition of a taller third building downstream of B1 generates much lower dilution upwind the stack in comparison with the previous case (Case 2). It is also observed that for a multiple building configuration $\mathrm{Sc}_{\mathrm{t}}$ has much less influence on dilution prediction downstream the stack but remains important for predictions upstream the stack, particularly for low M values. Figure 9 (a) corresponds to a $1 \mathrm{~m}$ stack at $\mathrm{M}=1$. This figure shows that $\mathrm{CFD}$ overestimates dilutions compared to wind tunnel at all receptors except near the stack, where the behaviour is inverted and CFD underestimates dilutions by about one order of magnitude. Downstream the stack CFD results are identical for $\mathrm{Sc}_{\mathrm{t}}=0.3$ and 0.7 and the predictions are overestimated by less than one order of magnitude, although the trend is comparable with wind tunnel. Wind tunnel generates very low dilutions within the first $0.05 \mathrm{~m}(10 \mathrm{~m})$ from the upwind edge of the building compared to CFD, which is conservative. Figure 9 (b) refers to the same case but considering $\mathrm{M}=3$. Again it is noticed that $\mathrm{Sc}_{\mathrm{t}}$ has much less influence on dilution prediction downstream the stack but remains important for predictions upstream the stack. CFD predicts higher dilutions than wind tunnel at $\mathrm{Sc}_{\mathrm{t}}=$ 0.1 and underestimates dilutions compared to wind tunnel at $\mathrm{Sc}_{\mathrm{t}}=0.7$. However, near the 
stack the behaviour is inverted. The results clearly indicate that the value of $\mathrm{Sc}_{\mathrm{t}}$ has a great impact on the prediction accuracy of mass transfer, as reported by Tominaga and Stathopoulos (2007). Therefore, a careful consideration of the flow characteristics is necessary to decide the appropriate value of $\mathrm{Sc}_{\mathrm{t}}$.

Figure 9

Figure 10 shows in detail the streamlines and dilution contour lines for Case 3 considering $\mathrm{Sc}_{\mathrm{t}}=0.3$ and 0.7. It is important to notice that Figure 10 (b) is a detailed visualization of Figure 6 (c) discussed previously. The plotted area corresponds to a $0.05 \mathrm{~m}(10 \mathrm{~m})$ air space from the roof and above B1. It must be mentioned that contour lines represent a locus of constant dilution, and hence regions where contour lines cluster together are regions of large dilution gradient. It is, however, interesting to look at the spatial distribution of dilution on Figures 10 (a) and (b), which show higher gradient downstream than upstream the stack. This result is in agreement with the highly turbulent pattern of this zone which is characterized by a very small mean velocity with high mixing rate.

Figure 10

\subsection{Pollutant effects on the adjacent buildings}

Normalized dilutions were also found on the windward wall of B3 for Case 3, where wind tunnel dilutions were found to be comparable with those from CFD, irrespective of the value of $\mathrm{Sc}_{t}$, as shown in Figure 11. This agreement indicates that CFD reproduces well dilutions in the downwind region of the stack between B1 and B3. It is important to note that the leeward wall of B3 is out of the recirculation zone caused by B2, as shown in Figure 5 (c), which is a comparatively less intense flow activity zone.

\section{Figure 11}

\section{CONCLUSIONS}


This paper reports and discusses CFD and wind tunnel simulations of pollutant dispersion around an isolated and a building as part of a cluster of taller buildings. The main conclusions can be summarized as follows:

- The results confirm that the pollutant plume behaviour is affected significantly by the surroundings. It is verified that pollutant dispersion from a rooftop stack of an isolated building is greatly influenced by the value of $\mathrm{Sc}_{\mathrm{t}}$. However, in the presence of adjacent buildings changes in $\mathrm{Sc}_{\mathrm{t}}$ do not have a major impact on plume dilutions, especially downstream the stack. A better agreement in terms of trend with wind tunnel data is generally observed at $\mathrm{Sc}_{\mathrm{t}}=0.3$ for the non-isolated building cases. The choice of a suitable $\mathrm{Sc}_{\mathrm{t}}$ requires a careful assessment of the plume structure in the built environment.

- CFD provides information about vortices which are formed in the leeward and between buildings. Knowing where these vortices are and how they interact with the surroundings is essential to the better understanding of the pollutant dispersion within an urban area.

- The pollutant re-ingestion on the emitting building is highly possible due to the presence of taller buildings placed upstream and downstream. Re-ingestion can be also problematic on the windward wall of the downstream building, as well as on the leeward wall of the upstream building.

- Though the calculations by ASHRAE-2007 are simple, in most cases the dilutions are much lower than those obtained from CFD and wind tunnel data making it necessary to re-visit the validity of ASHRAE-2007 formulations, which at present appear too conservative.

\section{REFERENCES}


ASHRAE 2007. Building Air Intake and Exhaust Design. Chapter 44, ASHRAE Applications Handbook. Atlanta: American Society of Heating, Refrigeration and AirConditioning Engineers, Inc, Atlanta, USA.

Blocken, B., Stathopoulos, T., Carmeliet, J., 2007. CFD simulation of the atmospheric boundary layer: wall function problems. Atmospheric Environment 41, 238-252.

Blocken, B., Stathopoulos, T., Saathoff, P., Wang, X., 2008. Numerical evaluation of pollutant dispersion in the built environment: comparisons between models and experiments. Journal of Wind Engineering and Industrial Aerodynamics 96, 1817- 1831.

Briggs, G.A., 1984. Plume rise and buoyancy effects in atmospheric science and power production. D. Randerson, ed. U.S Department of Energy, DOE/TIC-27601 (DE 84005177).

Cheng, Y., Lien, F.S., Yee, E., Sinclair, R., 2003. A comparison of large eddy simulations with a standard $k-\varepsilon$ Reynolds-averaged Navier Stokes model for the prediction of a fully developed turbulent flow over a matrix of cubes. Journal of Wind Engineering and Industrial Aerodynamics 91, 1301-1328.

Dobre, A., Arnold S.J., Smalley R.J., Boddy, J.W.D., Barlow, J.F., Tomlin, A.S., Belcher, S.E., 2005. Atmospheric Environment 39, 4647-4657.

Dyer, A.J., Bradley, E. F., 1982. An alternative analysis of flux-gradient relationships at the 1976 ITCE. Boundary Layer Meteorology 22, 3-19.

Flesch, T. K., Prueger, J. H., Hatfield, J. L., 2002. Turbulent Schmidt number from a tracer experiment. Agriculture and Forest Meteorology 111, 299-307.

FLUENT Inc., 2003. FLUENT 6.1 Users guide. FLUENT Inc, Lebanon. 
Franke J., Hellsten A., Schunzen H., Carissimo B., 2007. Best practice guideline for the CFD simulation of flows in the urban environment. Cost Action 732, Quality assurance and improvement of microscale meteorological models.

Hajra B, Stathopoulos T, Bahloul A., 2010. Assessment of pollutant dispersion from rooftop stacks: ASHRAE, ADMS and Wind Tunnel simulation. Journal of Building and Environment, vol. 45, 2768-2777.

Hefny M, Ooka R., 2009. CFD analysis of pollutant dispersion around buildings: effect of cell geometry. Building and Environment; 44(8), 1699-1706.

Hogstrom, U., 1996. Review of some basic characteristics of the atmospheric surface layer. Boundary Layer Meteorology 78, 215-246.

Koeltzsch, K., 2000. The height dependence of the turbulent Schmidt number within the boundary layer. Atmospheric Environment 34, 1147-1151.

Pruitt, W. O., Morgan, D. L., Lourence, F. J., 1973. Momentum and mass transfer in the surface boundary layer. Quarterly Journal of Royal Meteorological Society 99, 370-386.

Rotta, J.C., 1964. Temperaturverteilungen in der turbulenten grenzschicht an der ebenen platte. International Journal of Heat and Mass Transfer 7, 215-228.

Simiu, E., Scanlan, R. H., 1996. Wind effects on structures: fundamentals and applications to design. ${ }^{\text {rd }}$ Edition, Wiley Interscience Publication, USA.

Snyder, W. H., 1981. Guidelines for fluid modelling of atmospheric diffusion. EPA office of air quality, planning and standards, Research Triangle Park, NC, EPA-600/8-81-009.

Stathopoulos T., Lazure L., Saathoff P., Gupta A., 2004. The effect of stack height, stack location, and rooftop structures on air intake contamination- A laboratory and full scale 
study. IRSST research report R-392, Institut de recherche Robert-Sauvé en santé et en sécurité du travail, Montreal, Canada.

Stathopoulos, T., Hajra, B., Bahloul, A., 2008. Analytical evaluation of dispersion of exhaust from rooftop stacks on buildings. IRSST research report R-576, Institut de recherche Robert-Sauvé en santé et en sécurité du travail, Montreal, Canada.

Tominaga, Y., Stathopoulos, T., 2007. Turbulent Schmidt numbers for CFD analysis with various types of flowfield. Atmospheric Environment 41, 8091-8099.

Tominaga Y., Stathopoulos, T., 2009. Numerical simulation of dispersion around an isolated cubic building: Comparison of various types of k- $\varepsilon$ models. Atmospheric Environment 43, 3200-3210.

Wilson D.J., 1979. Flow patterns over a flat roofded buildings and application to exhaust stack design. ASHRAE Transactions 85, part 2, 284-295.

Wilson, D.J., Fabris, I., Chen, J., Ackerman, M., 1998. Adjacent building effects on laboratory fume hood exhaust stack design. ASHRAE Research Report 897, American Society of Heating and Refrigerating and Air-conditioning Engineers, Atlanta, USA. 

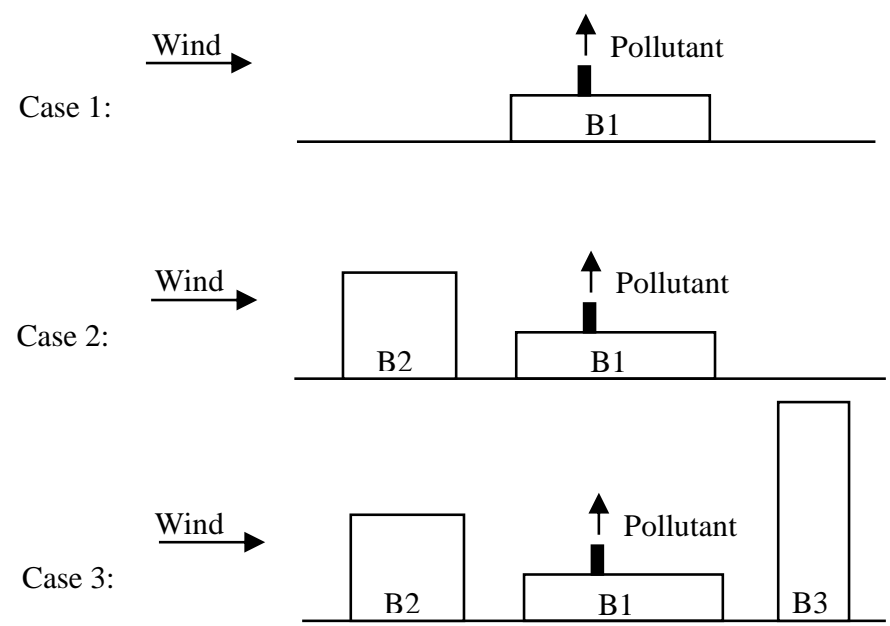

Figure 1: Cases studied 


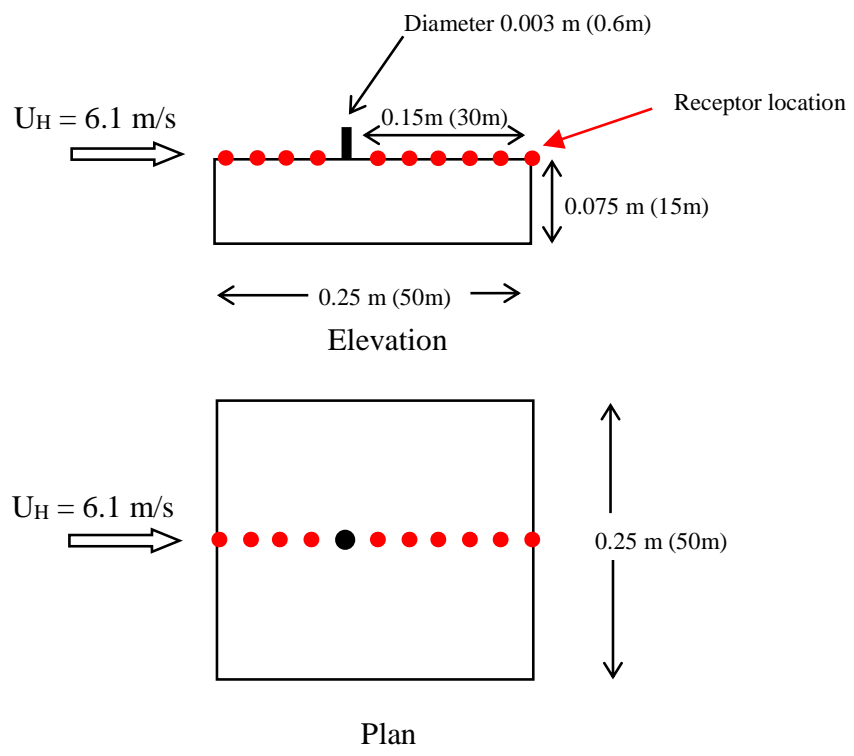

a)

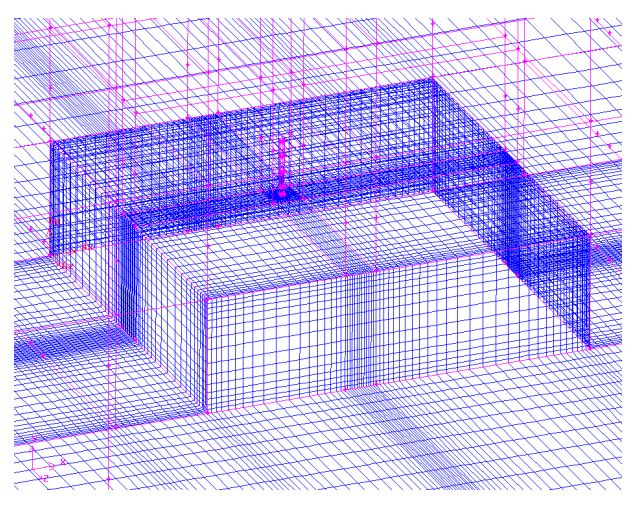

b)

Figure 2: Plan view and elevation (a) and mesh (b) of Building (B1) 


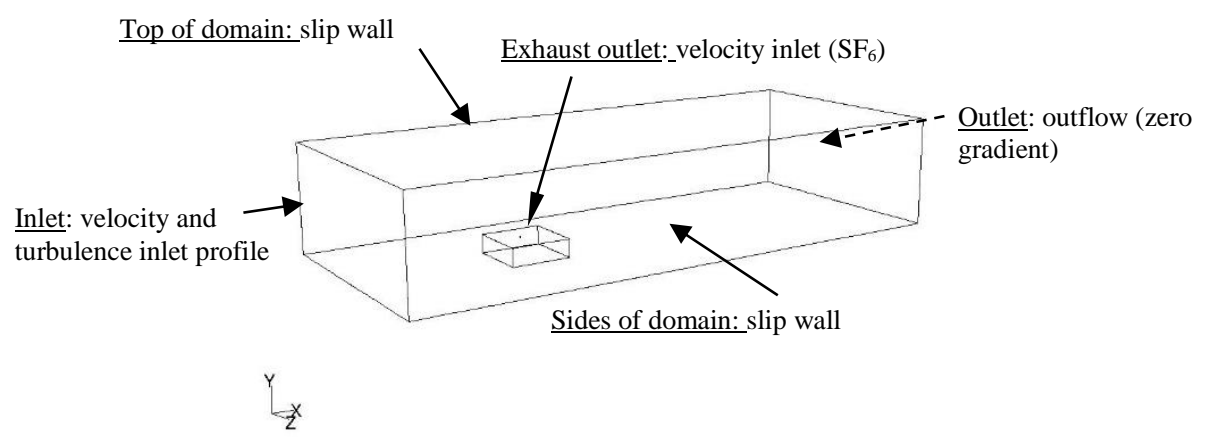

Figure 3: Boundary conditions of CFD model 


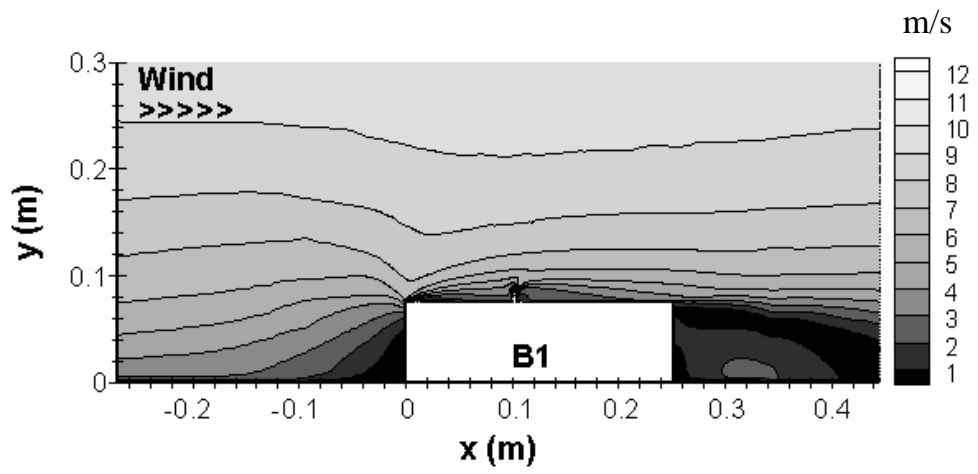

a)

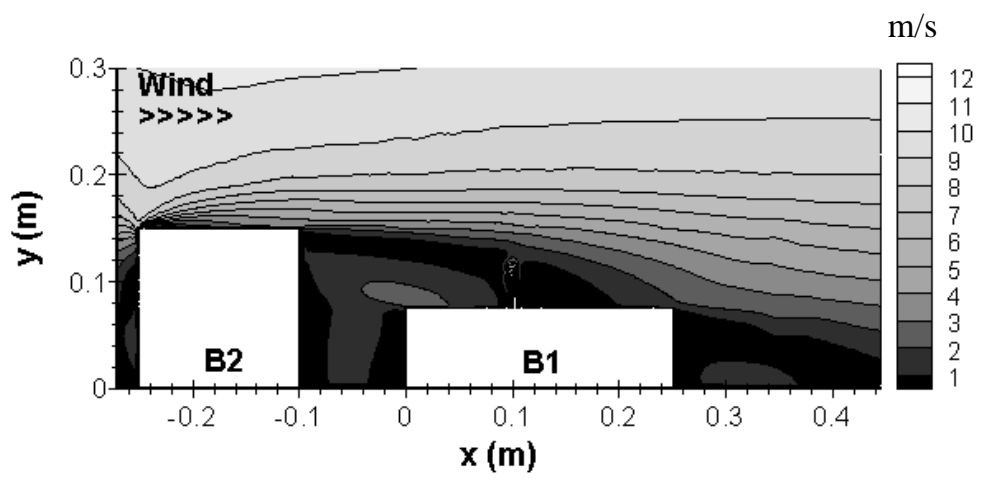

b)

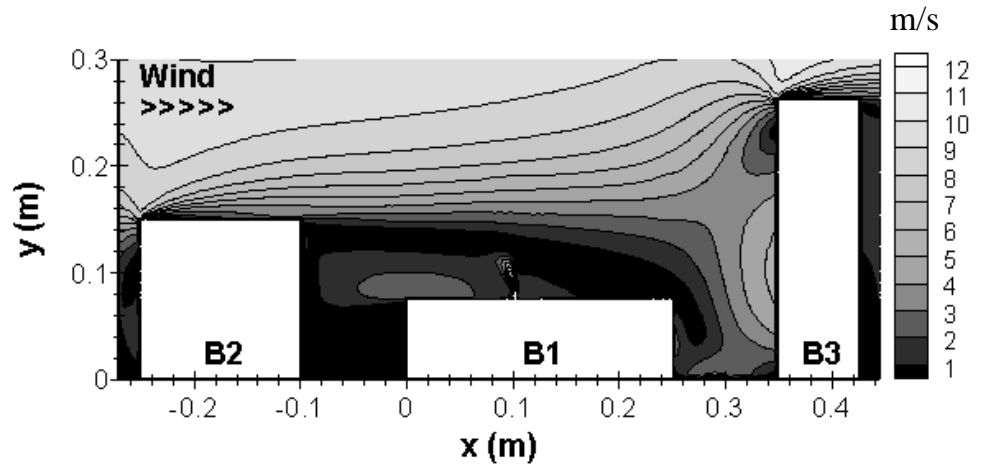

c)

Figure 4: Contours of mean velocity magnitude $(\mathrm{m} / \mathrm{s})$ for stack height $\mathrm{h}=1 \mathrm{~m}$ and exhaust momentum $\mathrm{M}=3$. a) Case 1, b) Case 2 and c) Case 3 . 

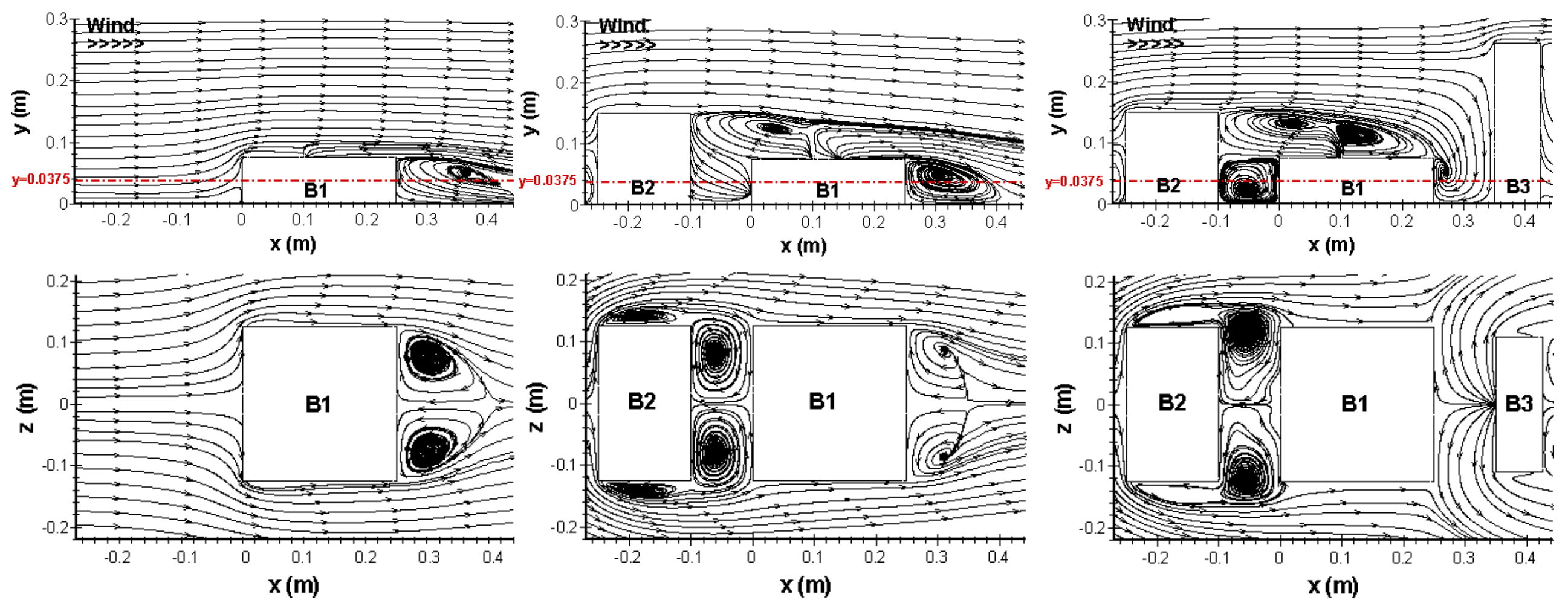

a)

b)

c)

Figure 5: Stream lines of vertical cross-section and plan view at height $\mathrm{y}=0.0375 \mathrm{~m}$. a) Case 1, b) Case 2 and c) Case 3 . 
Normalized dilution

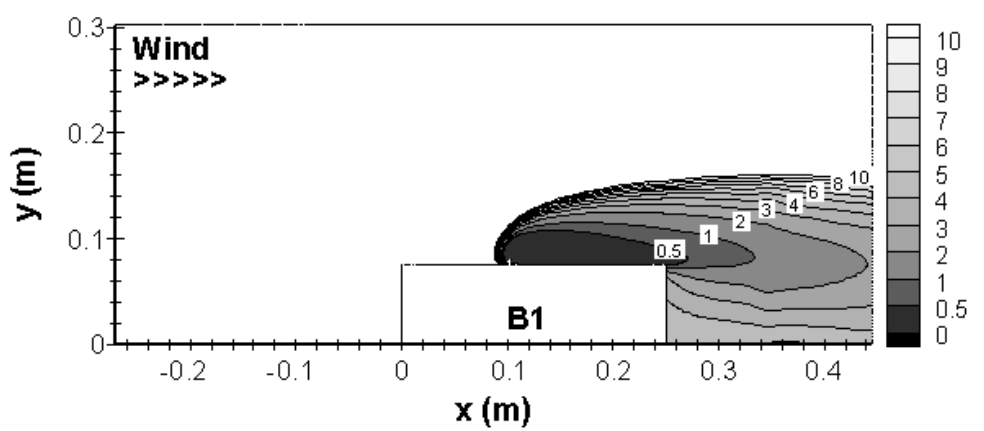

a)

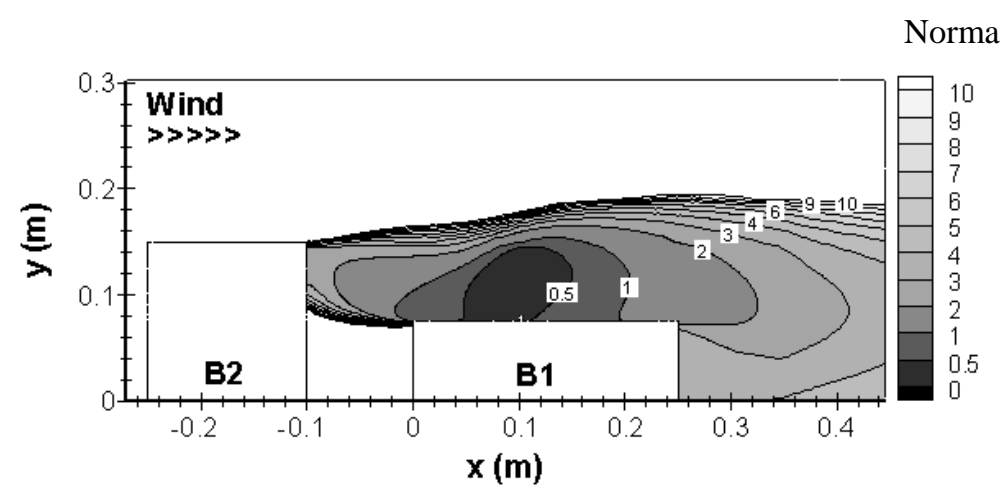

b)

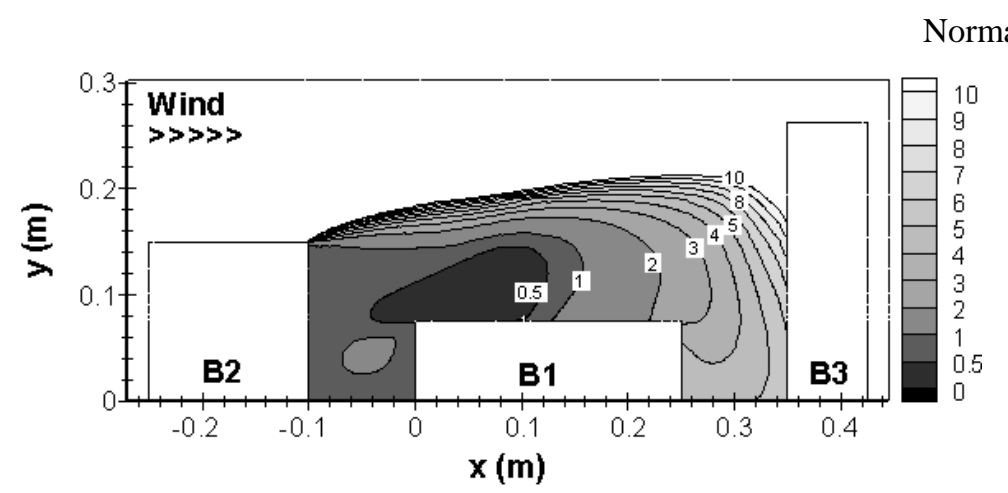

c)

Figure 6: Contours of normalized dilution for the same turbulent Schmidt number $\left(\mathrm{Sc}_{\mathrm{t}}=0.7\right)$, exhaust momentum $(\mathrm{M}=3)$ and stack height $(\mathrm{h}=1 \mathrm{~m})$. a) Case 1, b) Case 2, and c) Case 3. 


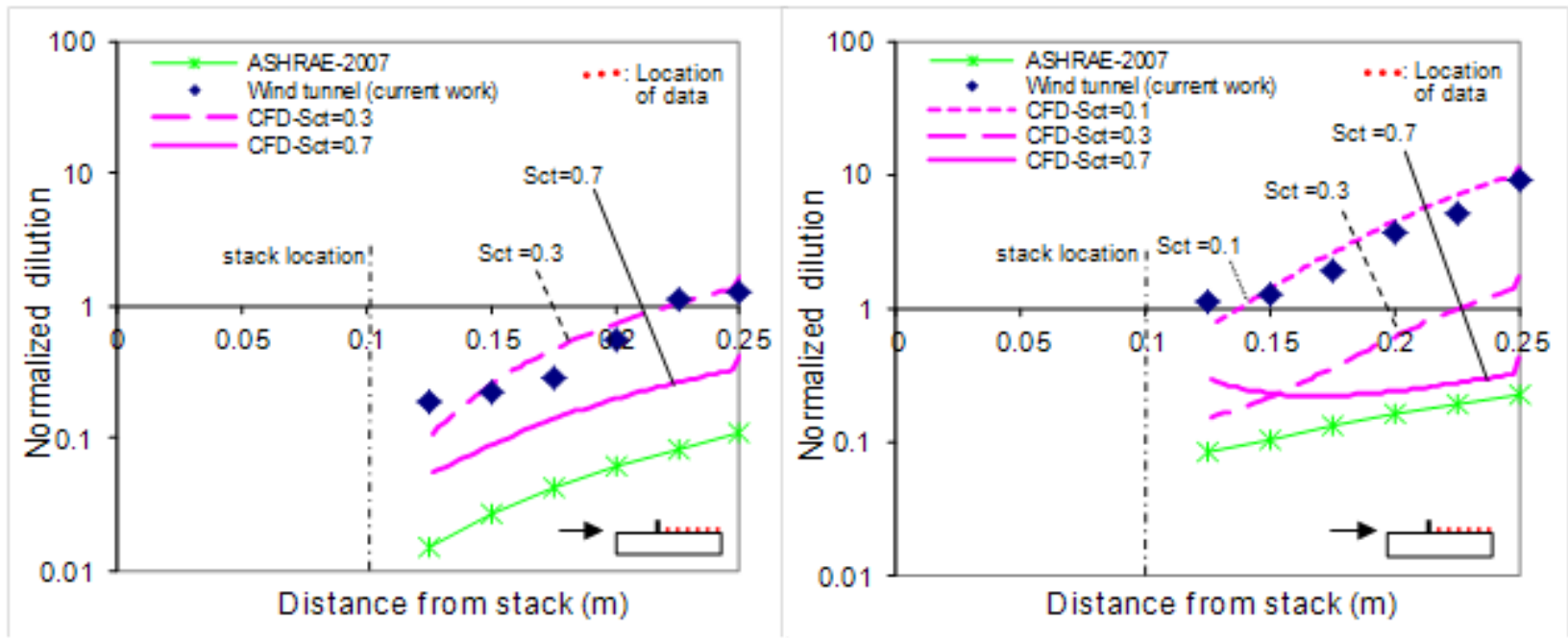

49

50

51

52

53

54

55

56 a)

b)

Figure 7: Normalized dilution on rooftop of $\mathrm{B}_{1}$ for Case 1 with: a) $\mathrm{M}=1$; b) $\mathrm{M}=3$
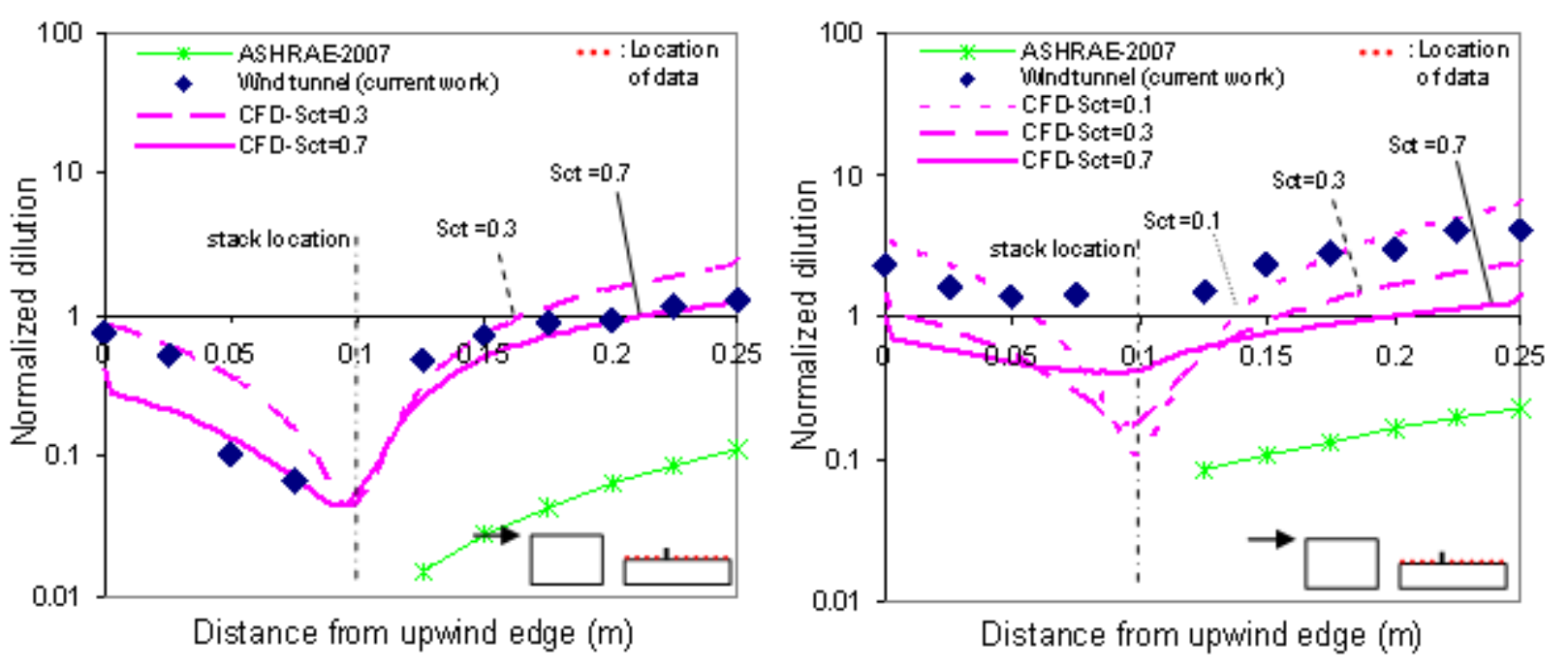

Figure 8: Normalized dilution on rooftop of $\mathrm{B} 1$ for Case 2 with: a) $\mathrm{M}=1$; b) $\mathrm{M}=3$ 


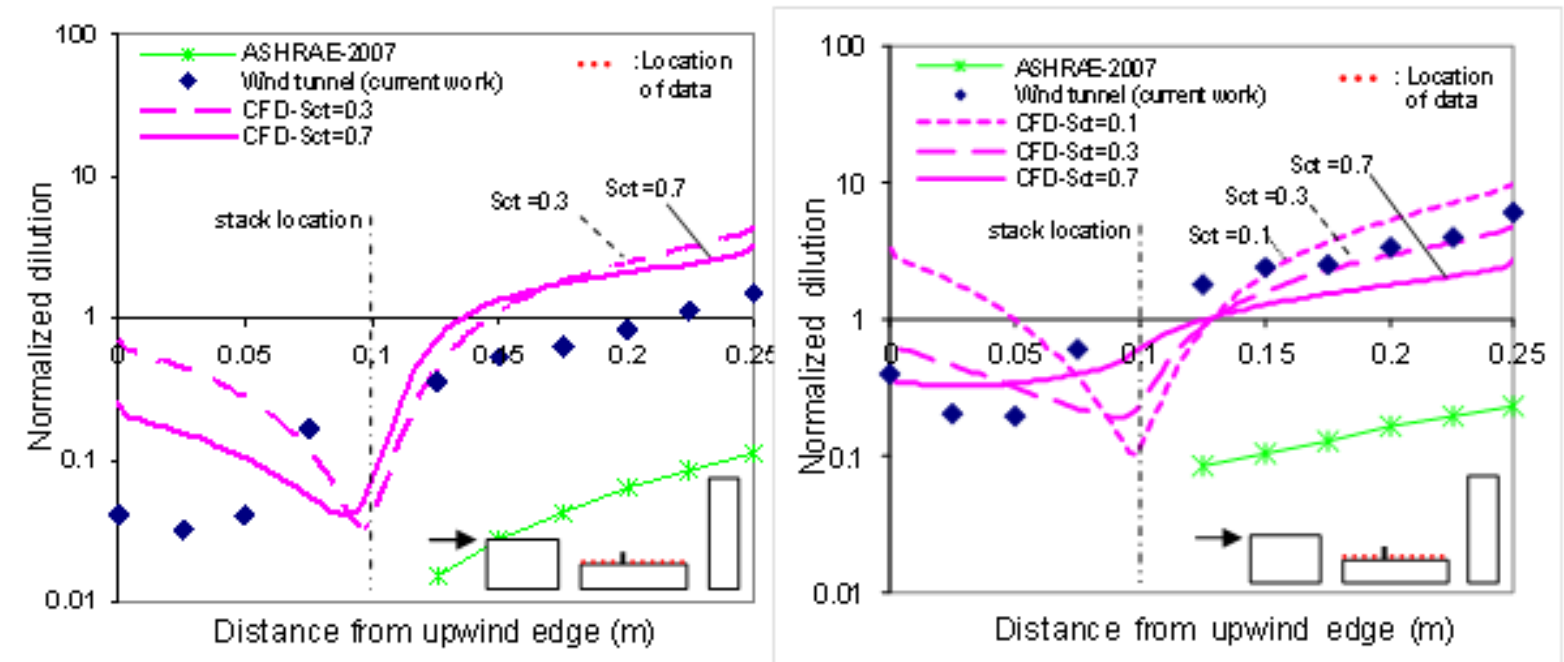

Figure 9: Normalized dilution on rooftop of $\mathrm{B} 1$ for Case 3 with: a) $\mathrm{M}=1$; b) $\mathrm{M}=3$

76

77 


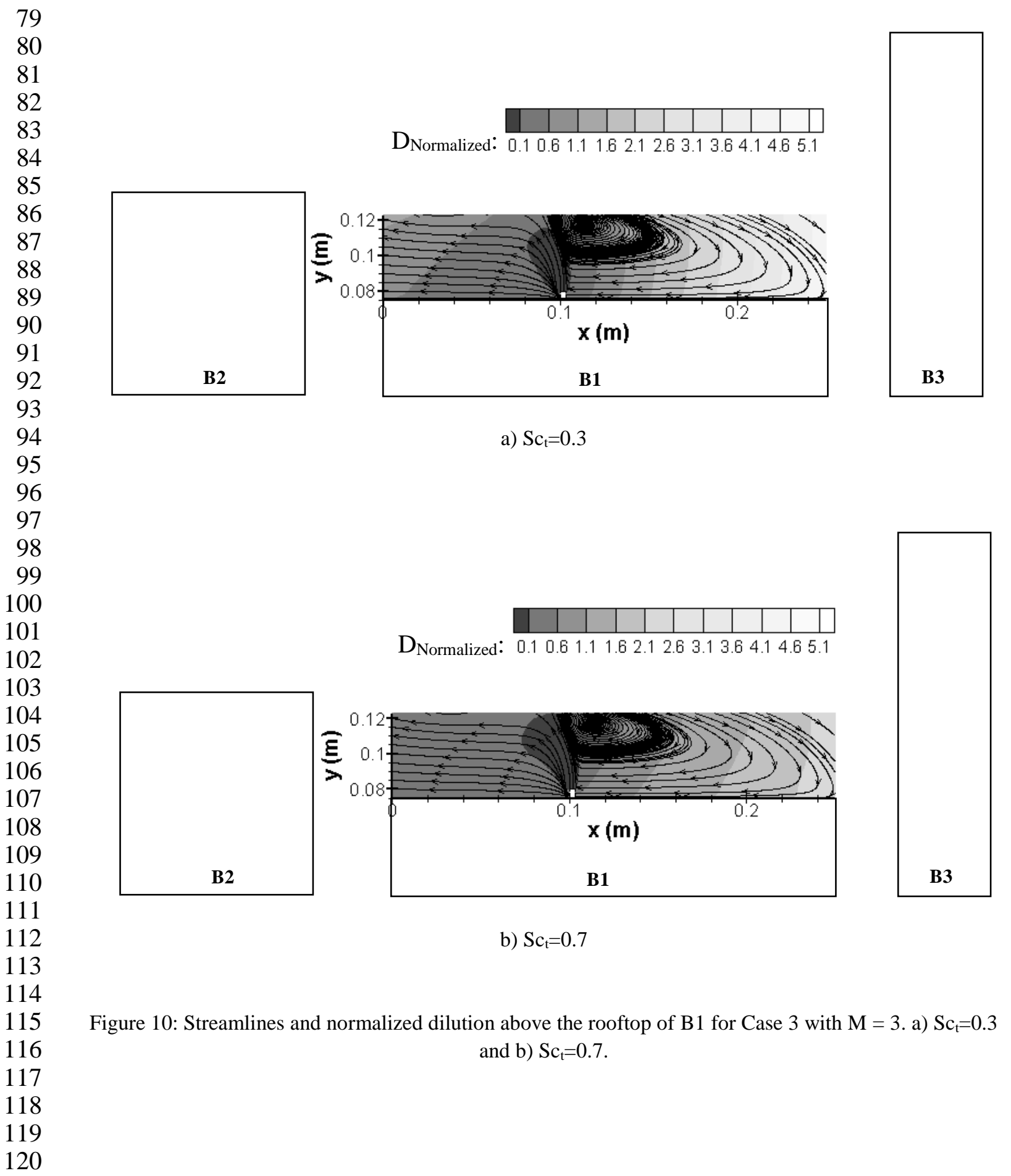




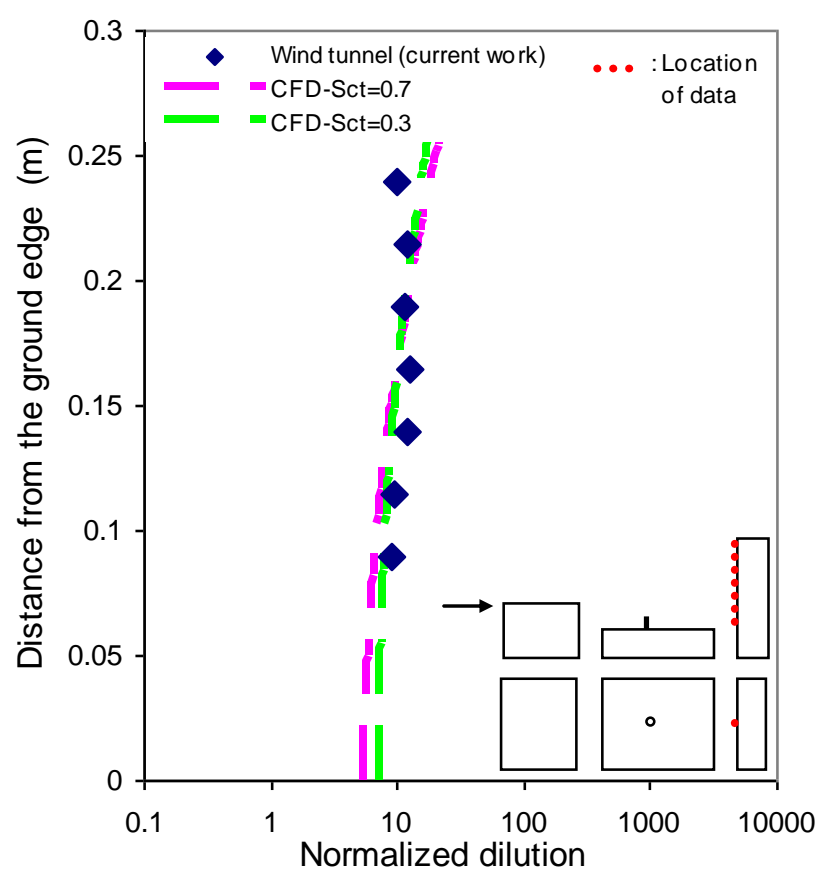

Figure 11: Normalized dilutions on the vertical wall of downstream building B3 for Case 3 with $\mathrm{Sc}_{\mathrm{t}}=0.3$ and 0.7 . 